\title{
UM MODELO DE SISTEMA DE INFORMAÇÃO CONTÁBIL PARA MENSURAÇÃO DO DESEMPENHO ECONOMICO DAS ATIVIDADES EMPRESARIAIS
}

\author{
Autor: Reinaldo Guerreiro \\ Professor - Assistente Doutor do Departamento de Contabilidade e \\ Atuaria da Faculdade de Economia e Administração e Contabilidade da USP
}

\section{Resumo}

O trabalho em pauta desenvolve-se a partir das seguintes premissas fundamentais: 1) as informações contábeis destinadas aos usuários externos não suprem adequadamente os modelos decisórios dos usuários internos da informação contábil; 2) Os usuários internos são os gestores, ou seja, os responsáveis pela tomada de decisões sobre os diversos eventos econômicos empresariais, tais como, compras, estocagem, produção, vendas, finanças, entre outros; 3) o resultado global da empresa é formado pela soma dos resultados analíticos das diversas atividades; 4) os responsáveis pela gestão econômica na sua esfera de responsabilidade necessitam de informações adequadas aos seus modelos de decisão; 5)os sistemas de informações devem dar o devido suporte informativo a cada etapa do processo de tomada de decisões; 6) os sistemas de informações de avaliação de desempenho devem impulsionar as ações dos gestores para a otimização do resultado global da entidade; 7)os conceitos de mensuração aplicados ao sistema de informação devem medir de forma lógica e racional os atributos dos objetos e eventos econômicos.

À partir das premissas consideradas é caracterizado dedutivamente um conjunto de conceitos que devem incorporar o modelo de sistema de informação contábil proposto.

Finalizando o modelo proposto, é explicada detalhadamente a lógica de processamento do sistema, que por sua vez, deriva naturalmente das premissas estabelecidas. Essa lógica é explicada com a utilização de um exemplo das operações de uma empresa operando em quatro exercícios sociais. Em cada um dos exercícios do exemplo, são demonstrados os lançamentos contábeis à luz da base conceitual do sistema, descrito o significado dessa contabilização, demonstrados os resultados econômicos apurados por área de resultado e o consolidado da empresa e, ainda, efetuada uma análise desses resultados para o atendimento do perfeito entendimento do modelo.

Deve ser observado que em função das limitações naturais de um trabalho desta natureza, a ênfase do modelo proposto foi concentrada tão somente na apuração de resultados econômicos por área de responsabilidade. Entendemos, contudo, que um sistema de informação contábil, deve incorporar um conjunto mais amplo de conceitos e atender a uma gama maior de premissas.

\section{PREMISSAS BÁSICAS PARA CONCEPÇÃO DO MODELO}

\section{Medida de Eficácia da Empresa}

A empresa é constituída sob o pressuposto da continuidade. A garantia de continuidade da empresa só é obtida quando as atividades realizadas geram um resultado liquido no mínimo suficiente para assegurar a reposição de todos os seus ativos consumidos no processo de realização de tais atividades.

Todas as estratégias, planos, metas e ações que a empresa implementa, devem objetivar em última instância a otimização do lucro. O lucro, portanto, é a melhor e mais consistente medida da eficácia da organização.

\section{Responsabilidade pela Geração do Lucro}

Tendo em vista a importância do conceito do lucro, questões que normalmente se colocam são: quem é responsável pela geração do lucro? O que (quais ) atividades estão contribuindo mais ou menos para a formação do lucro? Quem (quais gestores) estão obtendo melhores desempenhos? Essas questões constituem verdadeiros desafios das administrações modernas e raramente são respondidas a contento, pela inexistência de instrumental adequado que forneça as informações necessárias. Muito embora todas as atividades (o que) desenvolvidas pela empresa, bem como todos os gestores (quem) contribuem para a formação da empresa, observa-se que pela utilização de sistemas de informações tradicionais, simplesmente não são identificadas como as atividades analíticas contribuem no lucro global, e a perfomace dos gestores á medida por parâmetros físicos e por valores de c"custo" invés de resultados econômicos.

\section{Delegação e Controle}

As empresas em busca de continuidade, , do crescimento ou da expansão de suas atividades, em ambiente de concorrência acirrada, devem preparar-se no presente para atuar no futuro. 
O aumento da quantidade e da complexidade das operações indica automaticamente a necessidade de delegação de responsabilidade e autoridade a partir de certos níveis de atividade empresarial, a delegação não é mais uma questão de opção, é uma necessidade sem a qual a empresa coloca em risco a sua atuação futura, pois é impossível que somente umas poucas pessoas decidam tudo em todos os níveis.

A delegação embora necessária conduz a algumas questões. A primeira dela diz respeito à incerteza, ou seja, as pessoas que recebem, a delegação devem tratar com decisões sobre eventos futuros. Para minimizar as incertezas e os riscos, essas decisões devem ser tomadas dentro de um determinado "ritual" que envolve planejamento, coordenação, execução e controle das atividades, ou seja, o processo administrativo.

Uma segunda questão relativa à delegação diz respeito á eficácia dos gestores. A eficácia dos gestores requer além da competência natural exigida, uma participação e envolvimento profundo em todas as decisões no seu âmbito de atividades e em todas as fases do processo administrativo.

Uma terceira questão de delegação é quanto ao controle. Pode-se ter a falsa idéia de que a delegação conduza à perda de controle. Pelo contrario, através de um estilo participativo com envolvimento profundo dos gestores. É colocada uma etapa a mais no processo de controle é fortalecido à medida as decisões são tomadas respeitando-se o nível hierárquico, cabendo à Alta Direção a decisão final, e acionando um processo de "prestação de contas" de um nível hierárquico inferior para outro imediatamente superior.

Evidentemente este processo de prestação de contas exige a adoção de instrumentos, conceitos e critérios adequados e consistentes, que por um lado motivem os gestores e canalizem os seus esforços para a otimização do resultado global da empresa, e por outro lado, promova uma efetiva avaliação de desempenho.

\section{Papel dos gestores}

Os gestores são os responsáveis pela eficácia da empresa. Como o próprio nome esclarece, os gestores são os responsáveis pela gestão, administração ou processo de tomada de decisão. A gestão corresponde analiticamente ao processo de planejar, executar e controlar. Os gestores portanto não devem se limitar apenas à execução das atividades sob sua responsabilidade, mas também planeja-las e controla-las. Os gestores além de se envolverem com todas as etapas do processo decisório não podem furtar-se aos três aspectos intrínsecos a qualquer atividade, ou seja, o operacional, o econômico e o financeiro.

Os gestores competentes necessitam conhecer como esta se desenvolvendo a sua performance e normalmente desejam conhecer como o seu desempenho está contribuindo para o desempenho global da empresa.

Os gestores, via da regra, tem uma grande preocupação no sentido de que o seu desempenho não seja influenciado pelas ações e outros gestores, ou de variáveis fora de seu controle. Como são avaliados pelos resultados no seu âmbito de atuação, os gestores tendem a dar mais importância aos interesses particulares de sua área, em detrimento dos interesses globais da organização. A empresa como um empreendimento coletivo, exige para o seu sucesso, a definição de parâmetros que orientem a atuação das partes em beneficio do todo, principalmente considerando a maximização dos resultados setoriais não conduz necessariamente à otimização do resultado global da empresa.

\section{Aspectos Operacionais, Financeiros e Econômicos das Atividades}

Em cada atividade desenvolvida pela empresa observa-se três aspectos independentes. $O$ primeiro diz respeito à qualidade, quantidade, cumprimento de prazo, que denominamos operacional.

Esta atividades para serem realizadas consomem recursos e geram sempre algum tipo de beneficio na forma de produtos ou serviços. Aos recursos consumidos e aos produtos e serviços. Aos recursos consumidos e aos serviços gerados, podem ser associados valores econômicos (custo de recursos e receitas dos produtos e serviços), o que caracteriza o aspecto financeiro da atividade. Evidentemente os valores a prazo acarretam juros, os quais por sua vez impactam o resultado econômico da atividade.

\section{Informação para Gestão}

Os gestores tem uma grande dependência do recurso "informação".

A informação é matéria prima do processo de tomada de decisão.

A informação útil é aquela que atende as necessidades especificas dos gestores, segundo as áreas que atuam, operações que desenvolvem e conceitos que lhes façam sentido lógico. Os sistemas de informações contábeis devem ser configurados de forma a atender eficientemente as necessidades informativas de seus usuários, bem como incorporar conceitos, políticas e procedimentos que motivem e estimulem o gestor a tomar as melhores decisões para a empresa. 
A informação deve ter um sentido lógico para o gestor, portanto os conceitos de mensuração aplicados no sistema não podem ser dogmáticos, e sim racionais. O sistema de informações contábeis devem ser configurados de forma a atender eficientemente as necessidades informativas de seus usuários, bem como imcorporar conceitos,políticas e procedimentos que motivem e estimulem o gestor a tomar as melhores decisões para a empresa.

À informação deve ter um sentido lógico para o gestor, portanto os conceitos de mensuração aplicados no sistema não podem ser dogmáticos, e sim racionais. Os sistemas de informações contábeis tradicionais utilizam conceitos que não atendem as necessidades informativas para o gerenciamento das operações.

Dentre as diversas franquezas e insuficiências desses conceitos, destacam-se: soma de moeda de diferente poder aquisitivo, o valor de um bem é influenciado pela condição de pagamento, valores históricos defasados, não avaliação do impacto dos custos e receitas financeiros das atividades operacionais, dificuldade de análise de contribuição dos produtos, reconhecimento de resultados das diversas atividades produtivas da empresa, dificuldade de avaliação de desempenho das áreas em função de rateios arbitrários de gastos.

\section{As Premissas do Modelo Proposto}

Com base nas considerações efetuadas, estabelecemos o seguinte conjunto de premissas fundamentais, que devem nortear o desenvolvimento do sistema de informação contábil proposto:

1) As informações contábeis destinadas a usuários externos não suprem adequadamente os modelos decisórios dos usuários internos.

2) Os usuários internos são os gestores, ou seja, os responsáveis pela tomada de decisões sobre os diversos eventos econômicos empresariais, tais como, compras, produção, finanças, entre outros.

3) O resultado global da empresa é formado pela soma dos resultados analíticos das diversas atividades.

4) Os responsáveis pela gestão econômica na sua esfera de responsabilidade necessitam de informações adequadas aos seus modelos de decisão.

5) Os sistemas de informação contábeis devem dar o devido suporte informativo a cada etapa do processo de tomada de decisões.

6) Os sistemas de informações de avaliação de desempenho devem impulsionar as ações dos gestores para a otimização do resultado global da entidade.

7) Os conceitos de mensuração aplicados ao sistema de informação devem medir de forma lógica e racional os atributos dos objetos e eventos econômicos.

2- conceitos Fundamentais do Sistema derivados das Premissas

A seguir é descrito o significado dos conceitos básicos do modelo proposto, deduzidos a partir das premissas estabelecidas.

\section{Custo de Oportunidade}

Um conceito fundamental para a avaliação do resultado econômico das atividades e das áreas operacionais da empresa. no modelo do sistema de informação proposto, É o de custo de oportunidade.

Em termos práticos, o custo de oportunidade corresponde à remuneração mínima exigida pelos acionistas sobre o seu investimento na empresa.

Decompondo-se a empresa em áreas de responsabilidades de acordo com a sua estrutura de organização, é possível verificar que todos os ativos e passivos estão sob a responsabilidade de gestão de determinadas áreas.

Portanto no sistema proposto cada área deve "pagar" o custo de oportunidade do acionista sobre os ativos que administra a "receber" a receita de oportunidade sobre os passivos sob sua gestão.

Com o custo de oportunidade do acionista sobre os ativos é calculado com base em taxa de juro real de captação de mercado financeiro, a responsabilidade do acionista sobre os passivos operacionais (Fornecedores de bens e serviço) é calculado com base em taxa de juro real de aplicação do mercado financeiro, e a responsabilidade dos acionistas sobre os passivos exigíveis (empréstimos bancários)é calculada com base em taxa de juro real de captação do mercado financeiro.

Valor á vista

É o valor de um bem negociado na condição de pensamento à vista.

Custo Financeiro da Compra 
Corresponde à diferença entre o valor da compra na condição realizada e o valor da compra na condição de pagamento à vista.

Receita Financeira e Compra.

Corresponde ao "beneficio" que a área de compras gera para a empresa pela decisão à prazo e não à vista.

Esse valor é obtido da seguinte forma:

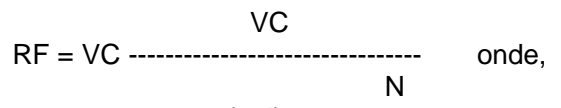

$\mathrm{RF}=$ Receita financeira da compra

$\mathrm{VC}=$ Valor da compra na condição realizada

I= Taxa de aplicação do mercado financeiro

$\mathrm{N}=$ Prazo de pagamento da compra

Resultado Financeiro da Compra

O resultado financeiro da compra corresponde à diferença entre a receita financeira da compra e o custo financeiro da compra.

Deve ser observado que o resultado financeiro da compra é função da decisão da área de compra de comprar à vista ou à prazo, da taxa de custo de oportunidade da operação (Taxa de aplicação do mercado financeiro), e a taxa de custo financeiro cobrado pelo fornecedor.

Recita Operacional de Compra

A receita operacional da compra corresponde à quantidade comprada e transferida para a área de estocagem, valorizada pelo preço de transferência. Neste exemplo consideramos o preço de transferência como o custo de reposição à vista.

Custo Operacional da Compra

O custo operacional da compra corresponde à quantidade comprada e transferida para estoques, valorizada pelo custo de reposição à vista.

Resultado Operacional da Compra

Corresponde à diferença entre a receita operacional e o custo operacional da compra.

Juro Diferido do Fornecedor

O juro diferido do fornecedor corresponde a contra-partida da receita financeira da compra, que ajusta o valor nominal de fornecedor a valor presente e que irá se converter em despesa no pagamento do compromisso com o fornecedor.

Resultado da Área de Compras

Corresponde à soma algébrica do resultado financeiro da compra com o resultado operacional da compra, deduzindo o valor das despesas departamentais da área.

Recita Financeira de Aplicações

Corresponde ao valor nominal (Correção monetária mais Juros) obtido pela aplicação da disponibilidade de caixa no mercado financeiro.

Perda Monetária no Caixa

Corresponde ao impacto inflacionário negativo sobre o valor da disponibilidade de caixa.

Custo de Oportunidade sobre Caixa

Corresponde à "cobrança" do custo de oportunidade de acionista sobre a parcela do seu capital investido no caixa, gerenciado pela área financeira da empresa.

Oportunidade do Acionista sobre Caixa

Caderno de Estudos nº 4, São Paulo, FIPECAFI - Março/1992 
O custo de oportunidade sobre o caixa é uma despesa da área financeira, enquanto a sua contra-partida denominada oportunidade do acionista sobre o caixa é uma receita da área de acionistas.

Resultado de Aplicações

Corresponde ao saldo obtido após a dedução do valor da perda monetária no caixa e do valor de custo de oportunidade sobre o caixa e do valor da receita financeira de aplicações.

Ganho Monetários sobre fornecedores

Corresponde ao impacto inflacionário positivo sobre o valor das contas a pagar a fornecedores, sob a gestão da área financeira.

Receita de Oportunidade sobre Fornecedores

Corresponde a responsabilidade do acionista sobre o valor de contas a pagar a fornecedores, reconhecida como receita da área financeira.

]Responsabilidade do Acionista sobre Fornecedores

Corresponde a contra-partida da recita de oportunidade sobre fornecedor da área financeira, sendo portanto, uma despesa da área de acionistas.

\section{Custo Financeiro de Fornecedores}

Correspondente ao custo financeiro do fornecedor do período da área financeira, reconhecido como custo no momento do pagamento compromisso com o fornecedor. Esse valor é baixado da conta juro diferido de fornecedor.

\section{Resultado de Fornecedores}

Corresponde ao valor do ganho monetário sobre fornecedores mais a receita de oportunidade sobre fornecedores menos o custo financeiro de fornecedores.

Receita Financeira de Clientes

Corresponde á receita financeira do cliente, reconhecida como receita da área financeira no momento do recebimento do valor devido pelo cliente. Esse valor é baixado da conta juro deferido de clientes.

Perda Monetária sobre Clientes

Corresponde ao impacto inflacionário negativo sobre o valor da conta a receber de clientes.

Custo de Oportunidade sobre Clientes

Corresponde a "Cobrança" do custo de oportunidade do acionista sobre a parcela do seu capital investido em contas a receber de clientes, gerenciado pela área financeira da empresa.

Oportunidades dos Acionistas sobre os Clientes

O custo de oportunidade sobre clientes é uma despesa da área financeira, enquanto a sua contra-partida denominada oportunidade do acionista sobre clientes, é uma receita da área de acionistas.

Resultado de Clientes

Corresponde ao saldo obtido pela dedução da perda monetária de clientes e do custo de oportunidade sobre clientes do valor da receita financeira de clientes.

Resultado da Área Financeira

Corresponde á soma algébrica dos resultados de todas as atividades da área financeira, deduzidas as despesas departamentais da área.

Ganho de Estocagem

O ganho real de estocagem corresponde à diferença entre o ganho nominal de estocagem e o custo de oportunidade inflacionário sobre o estoque. O ganho nominal de estocagem corresponde ao incremento do valor especifico do bem no período do tempo. 
O Custo de oportunidade inflacionário corresponde a valorização mínima (inflação) que o bem deveria proporcionar neste mesmo período de tempo.

Custo de Oportunidade sobre Estoques

Corresponde à "cobrança" do custo de oportunidade do acionista sobre a parcela do seu capital investido em estoques, gerenciado pela área de estocagem.

Oportunidade dos Acionistas sobre Estoques

O custo de oportunidade sobre estoques é uma despesa da área de estocagem, enquanto a sua contra-partida denominada oportunidade do acionista sobre estoques, é uma receita da área de acionistas .

Resultado da Á de Estoques

Corresponde ao saldo obtido após a dedução do valor do custo de oportunidades sobre estoques e das despesas departamentais da área, do valor do ganho real de estocagem.

Receita Operacional de vendas

Corresponde à quantidade vendida valorizada pelo preço de venda à vista.

Custo Operacional das Vendas

Corresponde a quantidade vendida valorizada pelo custo de reposição à vista na data da venda.

Resultado Operacional de Vendas

Corresponde a diferença entre a receita operacional e o custo operacional de vendas.

Receita Financeira da Venda

Corresponde a diferença entre o valor da venda na condição realizada e o valor da venda na condição de recebimento a vista.

Custo Financeiro de Venda

Corresponde ao "sacrifício" financeiro que a área comercial gera para a empresa pela decisão de vender a prazo e não à vista. Esse valor é obtido da seguinte forma:

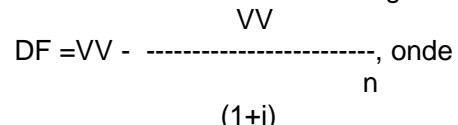

DF $=$ Custo Financeiro de Venda

$\mathrm{VV}=$ valor de Venda na Condição na Condição Realizada

I = Taxa de Captação do Mercado Financeiro

$\mathrm{N}=$ Prazo de Recebimento da Venda

Resultado Financeiro da Venda

Corresponde a diferença entre o valor da receita financeira da venda e o custo financeiro da venda.

Resultado da Área Comercial

Corresponde a soma algébrica do resultado financeiro e do resultado operacional da venda, deduzindo o valor das despesas departamentais da área.

Resultados das áreas

É obtido pelo somatório dos resultados das diversas áreas da empresa. Corresponde ao resultado econômico total (operacional e financeiro) de todas as atividades da empresa, após o "pagamento" do custo de oportunidade dos acionistas.

Resultado da Área-Acionistas

É obtida pela soma algébrica dos custos de oportunidade "cobrado" das diversas áreas e das receitas de oportunidade "pagas" á área financeira.

Resultado da Empresa 
Corresponde ao resultado das áreas operacionais mais o resultado da área-acionistas.

3- MODELO LÓGICO DO SISTEMA DE INFORMAÇÃO

Á lógica de funcionamento do modelo do sistema de informação proposto é explicada com base na utilização de um exemplo. São consideradas as operações de uma empresa em economia inflacionária, operando a partir do período T0 até o final do período T4. No fim do T0 houve uma integralização de capital em espécie no montante de $\$ 1000,00$. O numerário foi imediatamente aplicado no mercado financeiro, pelo prazo de um período, a taxa de $12 \%$ a . p . Na seqüência, para cada um dos períodos, são expostos os eventos ocorridos, o fluxo de contabilização dos eventos, a explicação dos lançamentos contábeis à luz da base conceitual do sistema, a demonstração de resultados de cada uma das áreas da empresa e o resultado consolidado, o balanço no fim do período e a explicação dos resultados apurados pelas áreas.

\section{EVENTOS - EXERCÍCIO T1}

No do exercício T1 ocorreram os seguinte eventos:

- compra `avista de 100 unidades de produto À pelo valor total de $\$ 575,00$ sendo que nesta data, o valor de reposição à vista é de $\$ 500,00$.

- Reconhecimento do resultado da aplicação no mercado financeiro efetuado no fim de T0.

- $\quad$ Aplicação da disponibilidade de \$1.120,00 no mercado financeiro, durante um período, á taxa de $12 \%$ ap.

- Inflação do período: $10 \%$ ap.

- Custo financeiro de captação: $13,30 \%$ ap.

- A contabilização dos eventos está demonstrada no quadro em anexo.

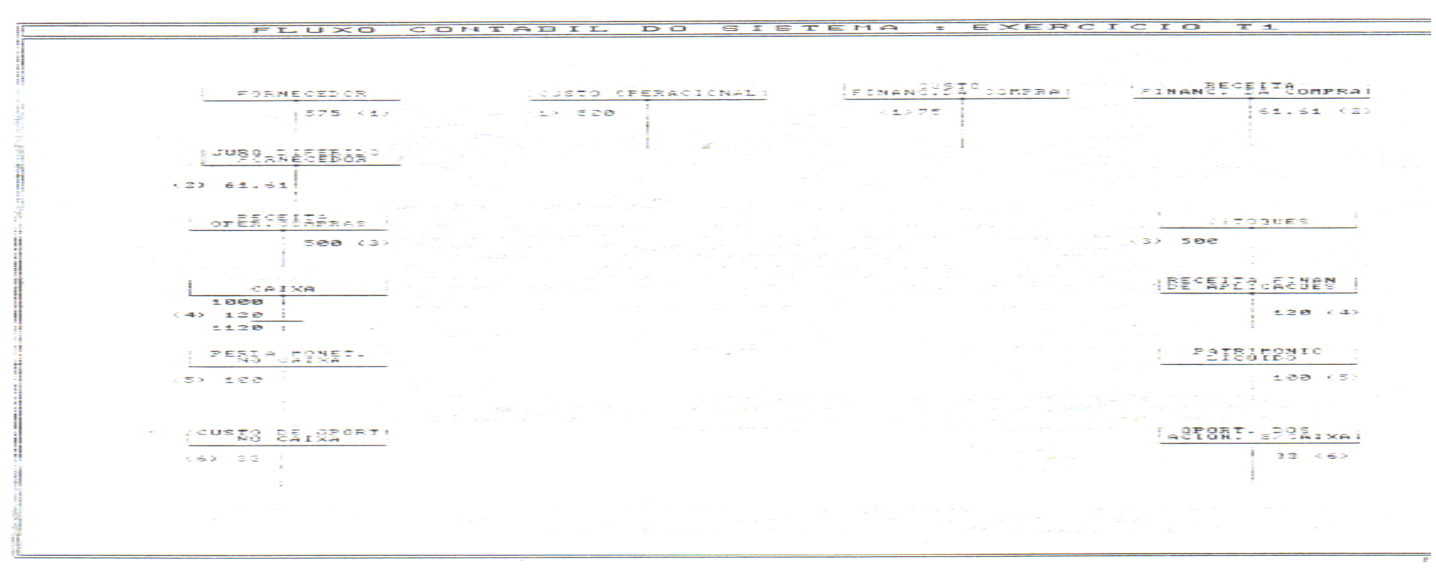

ANALISE DE CONTABILIZAÇÃO - EXERCICIO T1

\section{EVENTO: COMPRAS}

Registro no: Contabilização da compra

Este registro materializa o conceito que o "custo de um bem é seu valor a vista" e a diferença entre o valor pago e o custo á vista corresponde ao custo de financiamento da compra.

Foi contabilizado o valor nominal do compromisso assumido $(\$ 575,00)$ na conta "fornecedor" a contra-partida foi segregada em valor $(\$ 500,00)$ contabilizado na conta de "custo operacional" e em valor do custo financeiro $(\$ 575,00-\$ 75,00)$ registrado na conta "custo financeiro da compra".

Registro no 2: Contabilização da receita financeira da compra

A receita financeira da compra corresponde a "receita de oportunidade" gerada pela área de compras para a empresa. Pela decisão de comprar a prazo a área de compra permitiu que a empresa (através da área financeira, ou se a empresa 
estivesse com dificuldades de caixa, evitaria que esta captasse o numerário no mercado financeiro e incorresse em despesas financeira.

O valor de receita financeira foi obtido da seguinte forma:

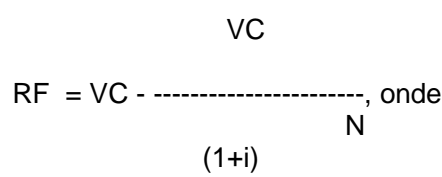

$\mathrm{RF}=$ Receita financeira da compra

VC $=$ Valor da compra na condição a prazo

$\mathrm{I}=$ Taxa de aplicação no mercado financeiro

$\mathrm{N}=$ Prazo de pagamento da compra

$\mathrm{RF}=575,00 \quad 575,00$

$\mathrm{RF}=61,61$

Deve ser observado que a contra-partida da receita financeira da compra é conta "juro diferido fornecedor" que ajusta o valor a prazo da conta "fornecedor" a valor presente.

Registro no 03: Contabilização da transferência do material para o estoque

O material foi transferido para estoque pelo seu valor econômico (custo de reposição à vista). Dependendo do papel de área de compras o valor econômico poderia corresponder a um preço a um preço de transferência interno.

\section{EVENTO: APLICAÇÃO DE DISPONIBILIDADE NO MERCADO FINANCEIRO}

Registro no 04: Contabilização da receita financeira de aplicações

O valor da receita $\$ 120.00$ foi obtido em função do montante aplicado, prazo decorrido e taxa de aplicação no mercado financeiro, sendo contabilizado na conta "receita financeira de aplicações".

Registro no 05: Contabilização do efeito inflacionário no valor do caixa.

O valor da perda monetária $(\$ 100,00)$ corresponde a aplicação da taxa de inflação do período sobre o valor da disponibilidade de caixa aplicado.

Registro no 06: Contabilização do custo de oportunidade da disponibilidade de caixa.

O Custo de oportunidade dos acionistas na disponibilidade de caixa corresponde a taxa de juro real (3\%) de captação do mercado financeiro aplicada sobre o valor inicial corrigido do caixa $(\$ 1100,00)$.

A taxa real de juro de captação: $(1,1330: 1,10)-1=3 \%$

Valor do custo de oportunidade: $\$ 1000,00 \times 1,10 \times 0,03=\$ 33,00$

Esse valor foi registrado na conta do "Custo de oportunidade no caixa" da área financeira e a contra-partida em contas na área de Acionistas "Oportunidade dos acionistas sobre o caixa".

DEMONSTRAÇÃO DE RESULTADOS - EXERCICIO 


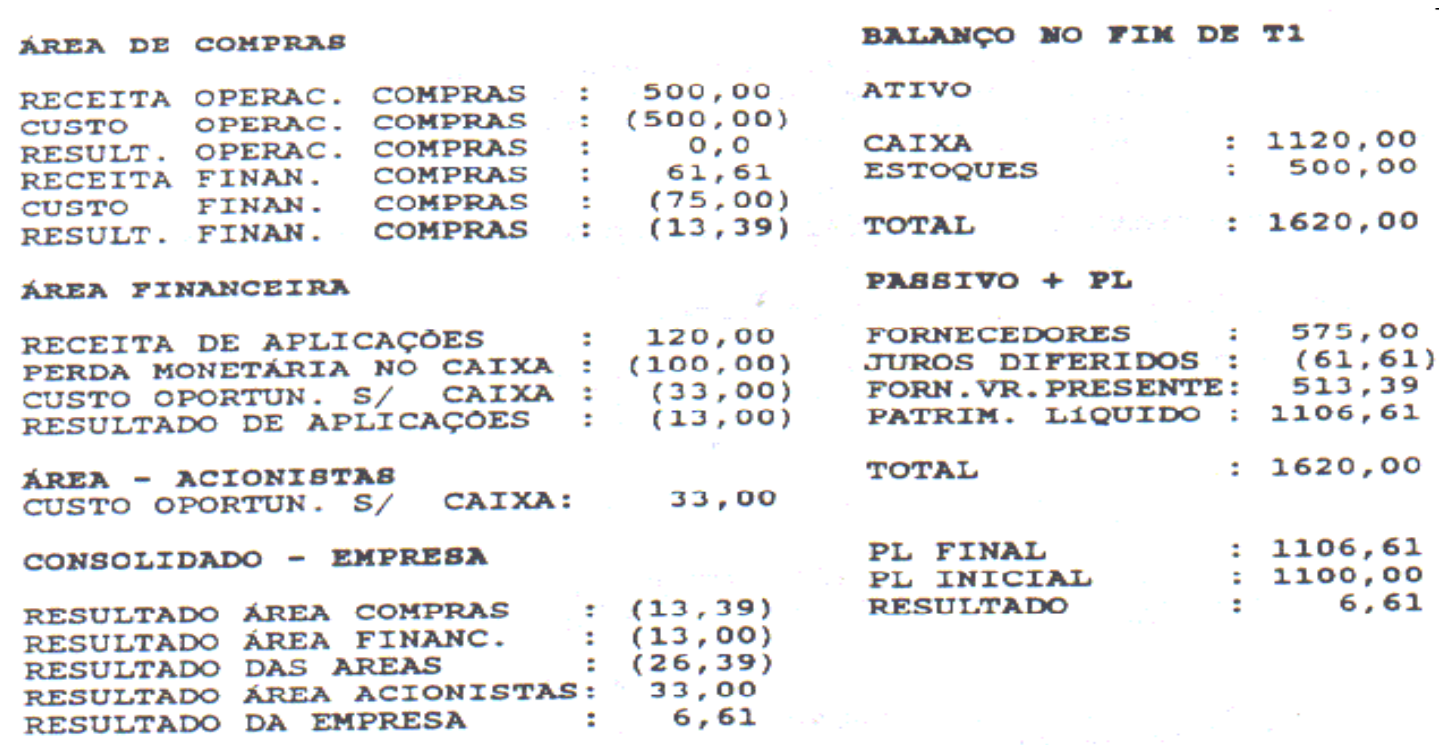

\section{ANÁLISE DOS RESULTADOS - EXERCICIOS T1}

\section{DESEMPENHO ECONOMICO DA ÁREA DE COMPRAS}

O resultado operacional da área de compras foi nulo em função da receita operacional ter sido equivalente ao valor do custo operacional.

O resultado financeiro da compra no entanto foi negativo porque a taxa de juro embutida pelo fornecedor (15\%) foi superior a taxa de oportunidade de operação (12\%). Teria sido melhor se a compra fosse efetuada na condição de pagamento á vista.

\section{DESEMPENHO ECONOMICO DA ÁREA FINANCEIRA}

O resultado econômico da área financeira foi negativo $(\$ 13,00)$ em função da cobrança do custo de oportunidade do acionista sobre o dinheiro aplicado. A receita da aplicação $(\$ 120,00)$ foi superior a perda monetária $(\$ 100,00)$ mas a margem não foi suficiente para cobrir o custo de oportunidades no caixa $(\$ 33,00)$.

Deve ser observado que no modelo proposto a aplicação no caixa resultará sempre um resultado econômico negativo, porque a receita financeira será obtida via taxa de aplicação e o custo de aplicação e o custo de oportunidade no caixa via caixa de captação.

\section{DESEMPENHO ECONOMICO DA ÁREA ACIONISTAS}

Essa área é uma unidade apenas contábil não fazendo parte da estrutura de organização. Tem o objetivo de acumular o custo de oportunidade cobrado das diversas áreas operacionais da empresa.

Nesse período teve o resultado positivo de $\$ 33,00$ obtido da área financeira.

\section{DESEMPENHO ECONOMICO CONSOLIDADO}

O desempenho global da em[presa nesse período considerando-se o resultado de todas as áreas inclusive a área de acionistas foi positivo em $\$ 6,61$.

O resultado econômico das áreas operacionais foi negativo em $(\$ 26,39)$.

\section{EVENTOS - EXERCICIO T2}

No fim do exercício T2 ocorreram os seguintes eventos:

pagamento do compromisso assumindo com fornecedor do produto À $(\$ 575,00)$.

- $\quad$ Reconhecimento do resultado da aplicação no mercado financeiro efetuado no fim de T1. 
Um Modelo de Sistema de Informação Contábil para Mensuração do Desempenho 10 Econômico das Atividades Empresariais

- $\quad$ Aplicação da disponibilidade de $\$ 679,40$ no mercado financeiro, durante o per'rodo, à taxa de $12 \%$ ap.

- Reconhecimento do resultado da estocagem do produto A, desde o fim de T1 até o fim de T2. O preço de reposição à vista do produto $\mathrm{A}$ no fim de T2 é de $\$ 6,00 / \mathrm{u}$.

- Inflação do período: $10 \%$ AP.

- Custo financeiro de captação: $13,30 \%$ ap.

A contabilização dos eventos está demonstrada no quadro em anexo.

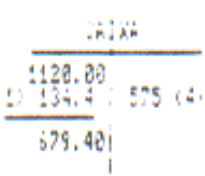

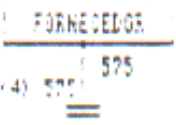

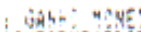

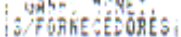

$T_{51.34}$

Pintronic I

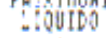

(6) 51.34 :

sonocues

9) 180 ?

¿อ?
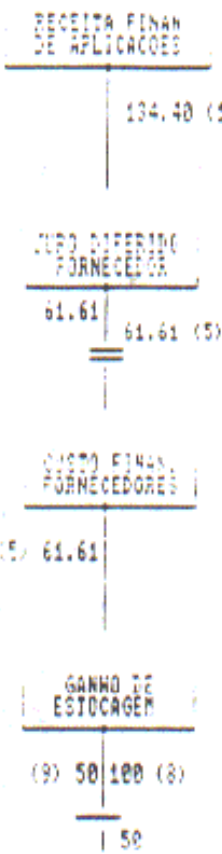

Thipines:
Elouit:

15019

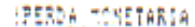

i inin

(1): ::

i

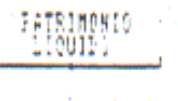

$:: 243$
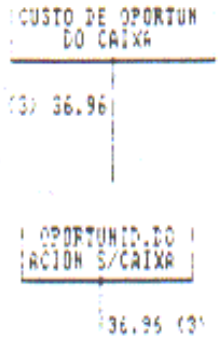

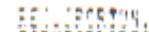

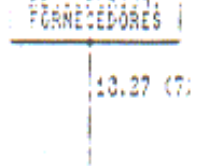

IESPQKS. ACIOK

S/FOR TE CEDDRES

(7) 10.27

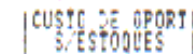

(10) 16.50

1

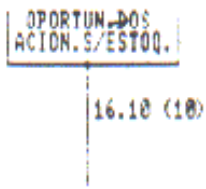




\section{ANÁLISE DA CONTABILIZAÇÃO - EXERCICIO T2}

\section{EVENTO: APLICAÇÃO DE DISPONIBILIDADE NO MERCADO FINANCEIRO}

Registro no 01: Contabilização da receita financeira de aplicações

O valor da receita $(\$ 134,40)$ foi obtido em função do montante aplicado, prazo decorrido e taxa de aplicação no mercado financeiro, contabilizado na conta da receita financeira de aplicação.

Registro no 02: Contabilização do efeito inflacionário no valor do caixa

O valor da perda monetária $(\$ 112,00)$ corresponde á aplicação da taxa de inflação do período sobre o valor da aplicação de caixa.

Registro no03 Contabilização do custo de oportunidade da aplicação financeira

O valor do custo de oportunidade da aplicação $(\$ 36,96)$ foi obtido pela aplica"cão da taxa real de custo de oportunidade de $3 \%$ (taxa real de captação no mercado financeiro)sobre o valor corrigido do caixa $(\$ 1120,00 \times 1,10=\$ 1232,00)$.

\section{EVENTO: PAGAMENTO DE COMPROMISSO COM FORNECEDOR}

Registro no 04: Contabilização do valor pago ao fornecedor

Corresponde ao pagamento do valor devido ao fornecedor $(\$ 575,00)$.

Registro n05: Contabilização do juro diferido de fornecedor como custo financeiro do período

No momento do pagamento do compromisso de compra ao fornecedor deve ser reconhecido o custo financeiro do fornecedor como uma despesa do período, ou seja, pelo transcurso do prazo de financiamento dado pelo fornecedor deve ser apropriado o juro correspondente. Assim o valor $\$ 61,61$ foi baixado da conta juro diferido de fornecedores e registrado na conta custo financeiro de fornecedores.

Registro nº 06: Contabilização do efeito inflacionário sobre o valor de fornecedores

O valor do ganho monetário $(\$ 51,34)$ foi obtido pela aplicação da taxa de inflação do período $(10 \%)$ sobre o valor ajustado da conta fornecedor $(575,00-61,61=513,39)$.

Registro n0: Contabilização da receita de oportunidade sobre fornecedores

Da mesma forma que a área financeira é cobras pelo custo de oportunidade sobre os ativos sob sua gestão, é beneficiada pela receita de oportunidade dos passivos que administra.

Á receita de oportunidade dos acionistas sobre o valor de fornecedores $(\$ 10,27)$ foi obtida pela aplicação da taxa de juro real $(1,8182 \%)$ de aplicação no mercado financeiro sobre o valor de fornecedor, corrigido pela inflação $(513,39 \times 1,10=564$, 73).

\section{EVENTO: ESTOCAGEM DE PRODUTO}

Registro n08: Contabilização do ganho pela valorização do produto estocado

O ganho pela valorização do produto estocado foi de $\$ 100,00$ ou seja, $\$ 600,00$ (valor do produto em T2) menos $\$ 500,00$ (valor do produto em T1). Esse valor é debitado ao estoque passa a expressar o seu verdadeiro valor econômico, sendo a contra-partida registrada na conta ganho de estocagem da área de estoques.

Registro $\mathrm{n}$ 009: Contabilização do efeito inflacionário no valor do estoque

O estoque é item monetário, portanto não é possível de perda inflacionária.

A inflação atua no estoque da mesma forma que o custo de oportunidade do acionista sobre os ativos. Assim o valor do registro $n^{\circ} 09(\$ 50,00)$ corresponde ao custo de oportunidade inflacionário sobre o estoque, obtido pela aplicação da taxa de inflação sobre o valor inicial do estoque.

Dessa forma é possível verificar que a valorização do estoque $(\$ 100,00)$ apurada no registro n0ㅇ é superior ao custo de oportunidade inflacionário $(\$ 50,00)$.

Faltaria ainda verificar se esse ganho liquido de $\$ 50,00$ cobre o custo de oportunidade do acionista.

Registro no10: Contabilização do custo de oportunidade sobre o estoque 
O valor do custo de oportunidade do estoque $(\$ 16,50)$ foi obtido pela aplicação da taxa de custo de oportunidade de $3 \%$ (taxa real de captação no mercado financeiro) sobre o valor corrigido do estoque $(\$ 500,00 \times 1,10=\$ 550,00)$.

DEMONSTRAÇÃO DE RESULTADOS - EXERCICIO T2

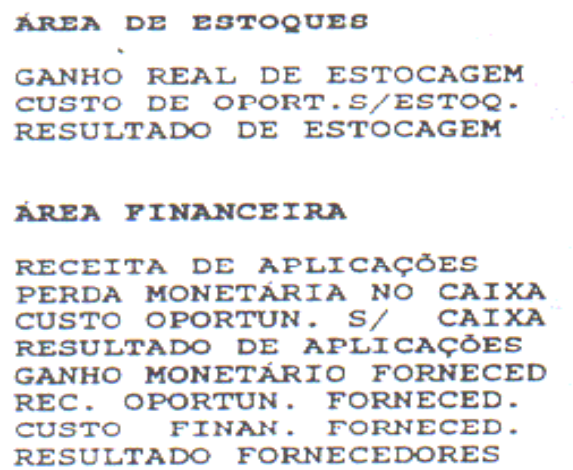

Banxpe No pIM DE T2

ATIVO

\section{CAIXA} ESTOQUES

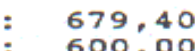

TOTAL

$: 1279,40$

PASSIVO + PL

112,00

$(36,96)$

$(14,56)$

51,34

$(61,61)$

0.0

PATRIM. IIQUIDO

TOTAL

$=1279,40$

$: 1279,40$

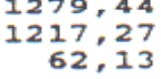

\section{ANÁLISE DOS RESULTADOS - EXERCICIO T2}

\section{DESEMPENHO ECONOMICO DA ÁREA FINANCEIRA}

O resultado econômico da área financeira foi formado pelos resultados de dois eventos. O primeiro evento corresponde à aplicação de disponibilidade no mercado financeiro que gerou um resultado negativo de $\$ 14,56$. Conforme já explicado esse resultado negativo deriva da cobrança do custo de oportunidade do acionista com base na taxa de captação é obtida em taxas normalmente inferiores.

Podemos interpretar esse resultado negativo como o custo da manutenção da liquides exigida pelas operações da empresa.

O segundo evento que compõe o resultado da área financeira é o pagamento de compromisso com fornecedor cujo resultado foi nulo.

\section{DESEMPENHO ECONOMICO DA ÁREA DE ESTOQUES}

O resultado econômico da área de estoques foi positivo em $\$ 33,50$.

O ganho de estocagem em termos líquidos (valorização do produto menos o custo de oportunidade inflacionário) foi $\$ 50,00$ muito superior ao custo de oportunidade exigido pelos acionistas sobre o investimento em estoque de $\$ 16,50$.

\section{DESEMPENHO ECONOMICO DA ÁREA DE ACIONISTAS}

Essa área acumula um resultado econômico de $\$ 43,19$, em função da "cobrança" do custo de oportunidade sobre os ativos utilizados pela área financeira e área de estoques, bem como pelo "pagamento" da receita de oportunidade sobre o passivo ganha pela área financeira (fornecedores).

\section{DESEMPENHO ECONOMICO CONSOLIDADO}

O resultado global da empresa nesse segundo período foi positivo em $\$ 62,13$.

Deve ser observado que o resultado econômico das áreas foi positivo em \$18,94 após o "pagamento" do custo de oportunidade dos acionistas de $\$ 43,19$. 


\section{EVENTOS - EXERCICIO T3}

No fim do exercício T3 ocorreram os seguintes eventos:

- $\quad$ venda de 50 unidades de produto a prazo por $\$ 720,00$, sendo que o valor a vista corresponde a $\$ 625,00$.

- $\quad$ Reconhecimento do resultado da aplicação no mercado financeiro efetuado no fim de T2.

- $\quad$ Aplicação de disponibilidade de $\$ 760,93$ no mercado financeiro, durante um período, á taxa de $12 \%$ ap.

- Reconhecimento do resultado da estocagem do produto A, desde o fim de T2 até o fim de T3. O preço de reposição à vista do produto $\mathrm{A}$ no fim de T3 é de $\$ 6,00 / \mathrm{u}$.

- Inflação do período: $10 \%$ ap.

- Custo financeiro de captação: $13,00 \%$ ap.

A contabilização dos eventos esta demonstrada no quadro em anexo .

\section{FLUXO CONTÁBIL DO SISTEMA : EXERCICIO T3}
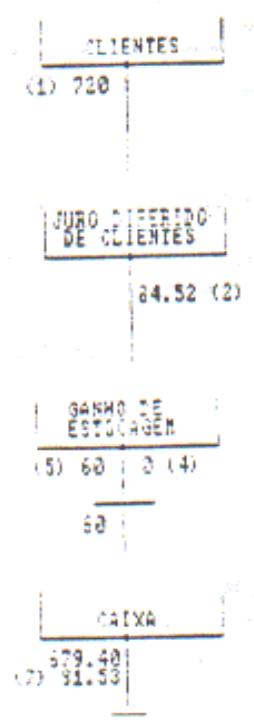

$769.92:$

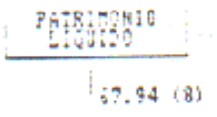

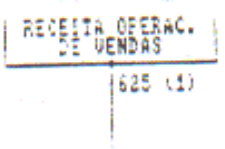
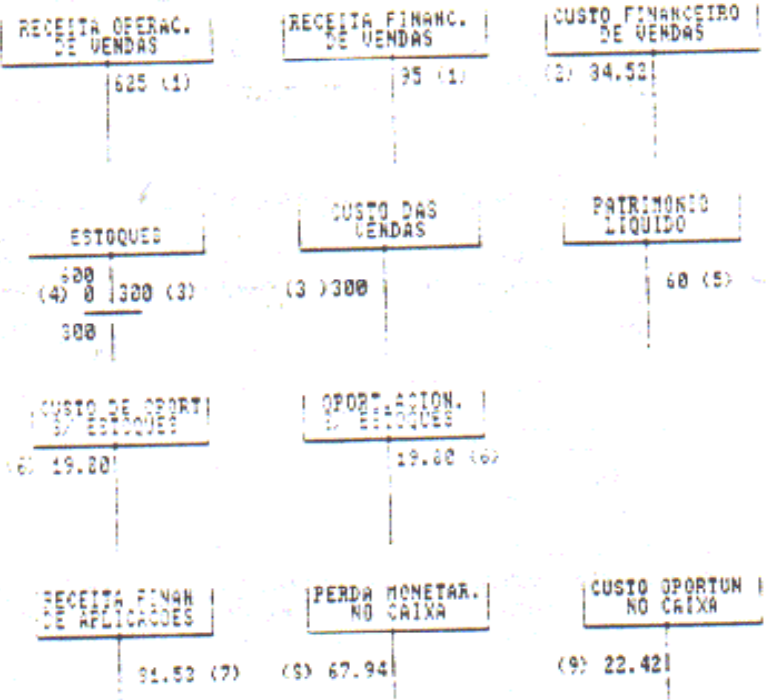

(⿻)

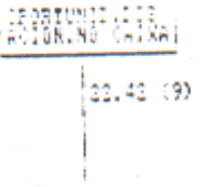


EVENTO: VENDA DO PRODUTO

Registro noํ: Contabilização da receita da venda

A receita nominal da venda $(\$ 720,00)$ foi decomposta em receita operacional $(\$ 625,00)$ e receita financeira $(\$ 720,00$ $\$ 625,00=\$ 95,00)$.

Registro no2: Contabilização do custo financeiro da venda

O custo financeiro da venda corresponde ao custo de oportunidade do ativo cliente gerado pela área de vendas na decisão de venda à prazo e não a vista.

O valor do custo financeiro de venda é obtido da seguinte forma:

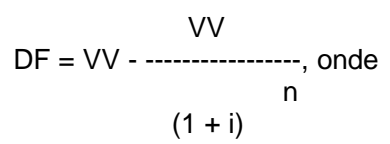

$\mathrm{DF}=$ custo financeiro da venda

$\mathrm{VV}=$ valor da venda na condição realizada (a prazo)

$\mathrm{I}$ = Taxa de captação no mercado financeiro

$\mathrm{N}=$ prazo para recebimento da venda

$\mathrm{DF}=720,00$ - $\begin{gathered}720,00 \\ (1,133)\end{gathered}$

A contra-partida do lançamento custo financeiro da venda corresponde ao juro diferido de clientes que ajusta o valor a prazo da venda ao correspondente valor presente.

Registro n03: Contabilização do custo operacional da venda

O custo operacional da venda corresponde ao produto da valorização das quantidades vendidas pelo custo de reposição à vista dos produtos.

\section{EVENTO: ESTOCAGEM DO PRODUTO}

Registro no 04: Contabilização do ganho de estocagem

Não houve aumento de preço especifico do produto, portanto, o ganho de estocagem foi nulo.

Registro n05: Contabilização do efeito inflacionário no valor do estoque

Como já explicado anteriormente o valor $\$ 60,00$ corresponde ao custo de oportunidade inflacionário sobre o estoque obtido pela aplicação da taxa da inflação $(10 \%)$ sobre o saldo inicial do estoque $(\$ 600,00)$.

Registro no06: Contabilização do custo de oportunidade sobre o estoque.

O valor do custo de oportunidade do estoque $(\$ 19,80)$ foi obtido pela aplicação da taxa real do custo de oportunidade de $3 \%$ sobre o valor corrigido do estoque $(\$ 600,00 \times 1,10=\$ 660,00)$.

\section{EVENTO: APLICAÇÃO DE DISPONIBILIDADE NO MERCADO FINANCEIRO}

Registro no 07: Contabilização da receita financeira de aplicações

Corresponde ao valor obtido $(\$ 81,53)$ pela área financeira pela aplicação da disponibilidade $(\$ 679,40)$ no mercado financeiro à taxa de $12 \%$.

Registro $\mathrm{n}^{\circ}$ : Contabilização do efeito inflacionário sobre o valor da aplicação financeira

O valor da perda monetária da aplicação $(\$ 67,94)$ foi obtido pela incidência da taxa de inflação do período $(10 \%)$ sobre o valor do saldo inicial na disponibilidade aplicada $(\$ 679,40)$.

Registro n0ㅜ: Contabilização do custo de oportunidade da aplicação financeira 
O valor do custo de oportunidade da aplicação $(\$ 22,42)$ foi obtido pela aplicação da taxa real de custo de oportunidade de $3 \%$ sobre o valor corrigido de caixa $(\$ 679,40 \times 1,10=\$ 747,3)$.

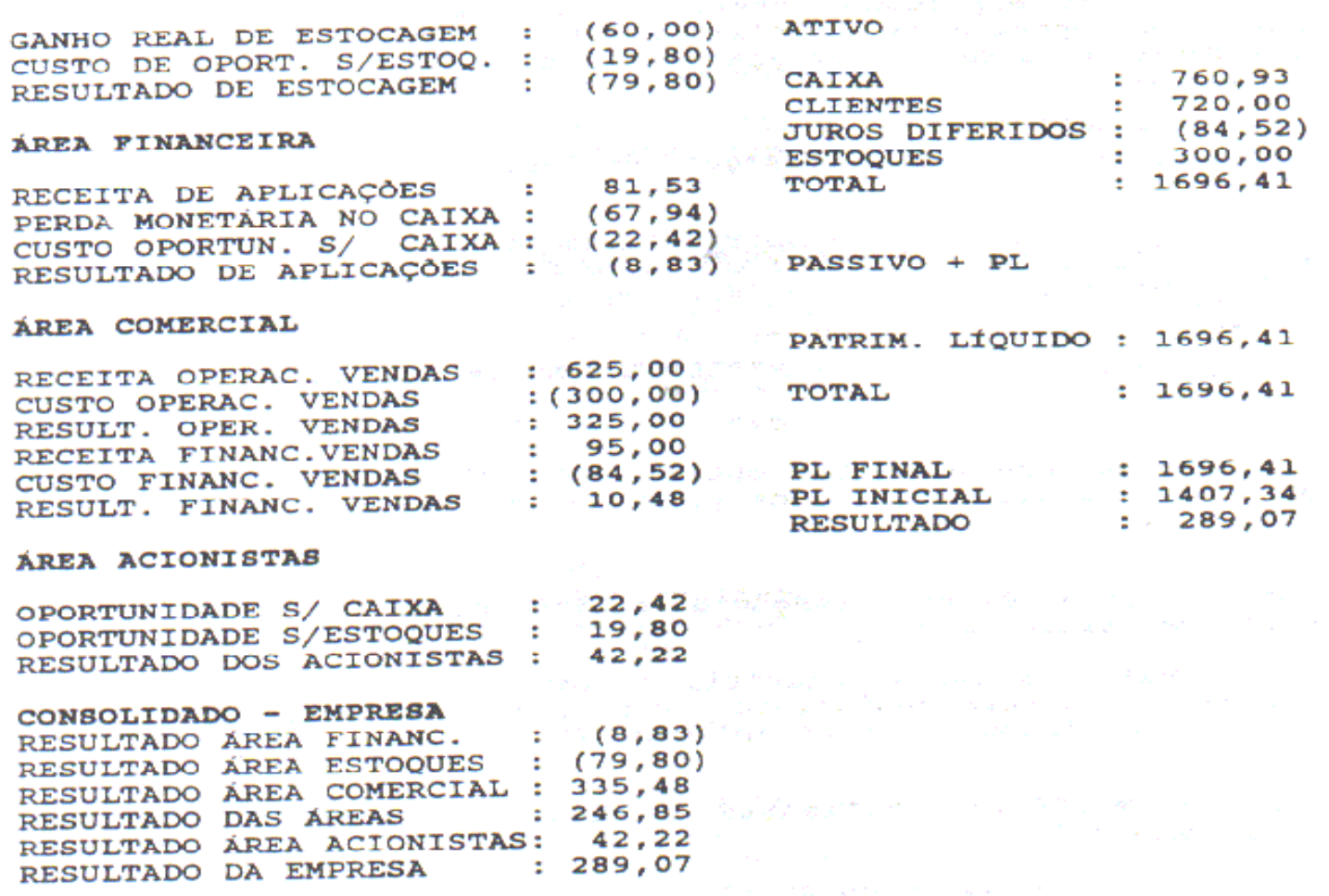

\section{ANALISE DOS RESULTADOS- EXERCICIO T3}

\section{DESEMPENHO ECONOMICO DA ÁREA COMERCIAL}

O resultado econômico proporcionado pela área comercial foi positivo em $\$ 335,48$, em função do resultado operacional de $\$ 325,00$, do resultado financeiro de $\$ 10,48$. O resultado financeiro da venda positivo demonstra que no preço a prazo foram embutidos juros superiores $(15,2 \%)$ a perda inflacionária $(10 \%)$ mais o custo de oportunidade real $(3 \%)$.

\section{DESEMPENHO DA ÁREA ECONOMICA FINANCEIRA}

A área financeira apresentou um resultado negativo de $\$ 8,83$ na aplicação da disponibilidade no mercado financeiro.

\section{DESEMPENHO ECONOMICO DA ÁREA DE ESTOQUES}

O resultado econômico da área de estoques foi negativo em $\$ 79,80$. Deve ser observados que este valor deriva do ganho de valorização produto (zero) menos o custo de oportunidade inflacionário $(\$ 60,00)$ e o custo de oportunidade real dos acionistas $(\$ 19,80$.).

\section{DESEMPENHO ECONOMICO DA ÁREA DE ACIONISTAS}

O resultado da área de acionistas foi positivo em $\$ 42,22$ em função da "cobrança" do custo de oportunidade pelos ativos geridos pela área financeira e área de estoques.

\section{DESEMPENHO ECONOMICO CONSOLIDADO}

O resultado econômico global da empresa foi positivo em \$289,07.

O resultado econômico global das áreas também foi positivo $(\$ 246,85)$, em função do bom resultado gerado pela área comercial.

EVENTOS - EXERCICIO T4 
No fim do exercício T4 ocorreram os seguintes eventos:

recebimento de $\$ 720,00$ de clientes

- $\quad$ reconhecimento do resultado da aplicação no mercado financeiro efetuado no fim de T3.

- Reconhecimento do resultado da estocagem do produto A, desde o fim de T3 até o fim de T4. O preço de reposição à vista do produto a no fim de $\mathrm{T} \$$ é de $\$ 8,00 / \mathrm{u}$.

- Inflação do período: 10\% ap.

- Custo financeiro de captação: 13,30 ap.

A contabilização dos eventos esta demonstrada no quadro em anexo.

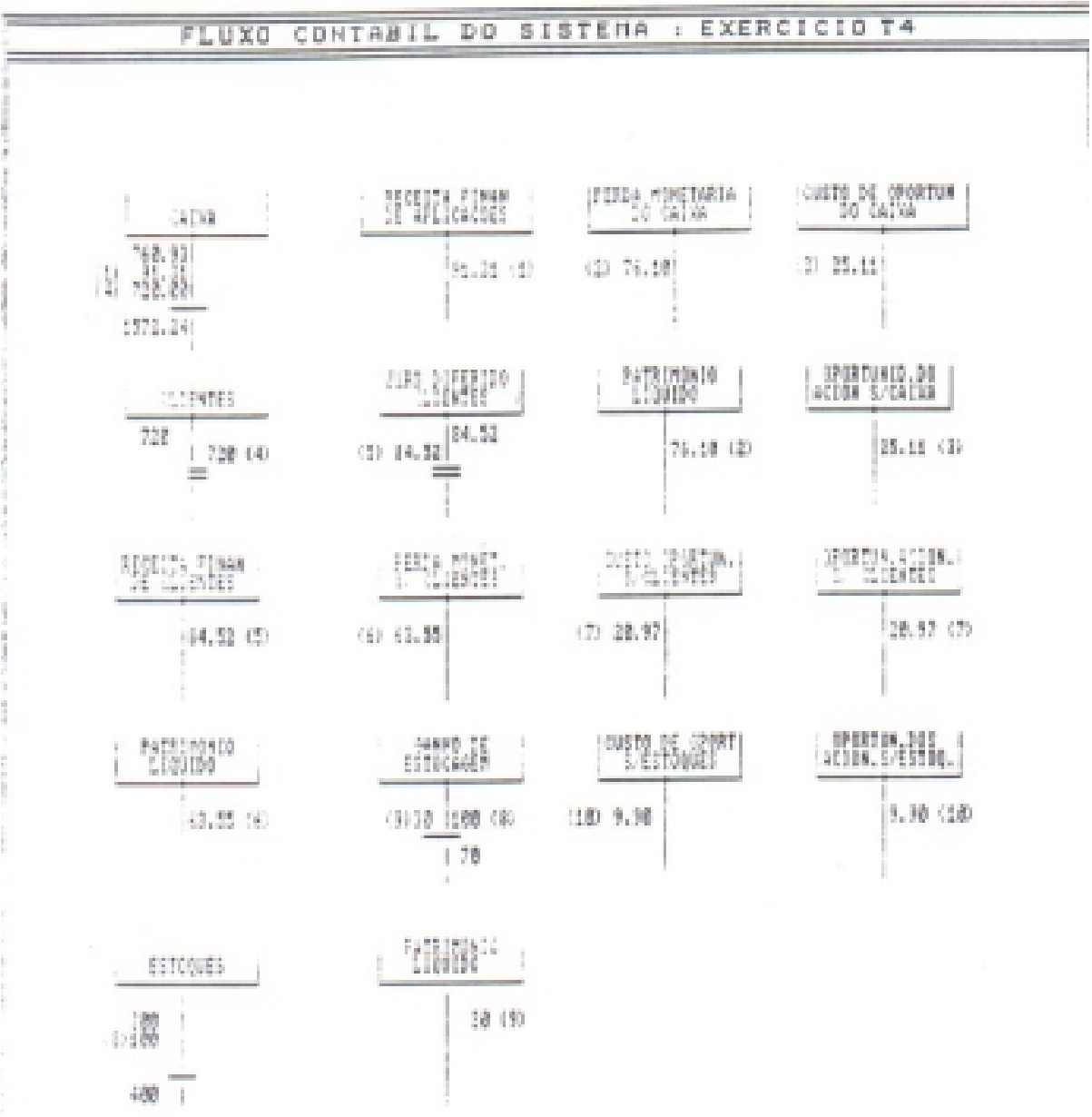

ÀNALISE DE CONCENTABILIZAÇÃO - EXERCICIOO T4

EVENTO: APLICAÇÃO DE DISPONIBILIDADE NO MERCADO FINANCEIRO

Registro nำ1: Contabilização da receita financeira de aplicação.

O valor contabilizado como receita financeira de aplicações $(\$ 91,31)$ foi obtido em função do valor aplicado de $\$ 760,93$ à taxa de $12 \%$ a .p..

Registro no2: Contabilização do efeito inflacionário sobre o valor da aplicação financeira. 
O valor contabilizado como perda monetária do caixa $(\$ 76,10)$, foi obtido pela incidência da taxa de inflação do período $(10 \%)$ sobre o valor do saldo inicial da disponibilidade $(\$ 760,93)$.

Registro no 3: Contabilização do custo de oportunidade da aplicação financeira.

O valor do custo de oportunidade da aplicação da taxa real de custo de oportunidade da aplicação financeira.

O valor do custo de oportunidade da aplicação $(\$ 25,11)$ foi obtido pela aplicação da taxa real de custo de oportunidade de $3 \%$ sobre o valor corrigido da aplicação $(760,93 \times 1,10=837,02)$.

\section{EVENTO: RECEBIMENTO DE CLIENTES}

Registro no4: Contabilização do valor a receber do cliente

Na data do vencimento o valor recebido do cliente $(\$ 720,00)$ foi baixado da conta clientes contra a conta caixa.

Registro n5 Contabilização do juro diferido de clientes como receita financeira financeira do período

No momento do recebimento (vencimento) do valor do cliente deve ser reconhecida a receita financeira de clientes como uma receita do período. Assim o valor $\$ 63,55$ foi baixado da conta de juro diferido de clientes e contabilizado na conta receita financeira de clientes.

Registro no 6 Contabilização do efeito inflacionário sobre o valor de clientes

O valor contabilizado a conta perda monetária sobre clientes $(\$ 63,55)$ foi obtido pela aplicação da taxa de inflação do período (10\%) sobre o valor ajustado da conta clientes $(\$ 720,00-\$ 24,52=635,48)$.

Registro nำ: Contabilização de custo de oportunidade sobre clientes

O valor do custo de oportunidade sobre clientes $(20,97)$ foi obtido pela aplicação da taxa de custo de oportunidade de $3 \%$ sobre o valor ajustado de clientes corrigido $(\$ 635,48 \times 1,10=\$ 699,02)$.

\section{EVENTO: ESTOCAGEM DO PRODUTO}

Registro no8: Contabilização do ganho de estocagem

O ganho $(\$ 100,00)$ pelo aumento do valor dos produtos foi registrado na conta ganho de estocagem, tendo como contrapartida o registro na conta de estoques.

Registro no9: Contabilização do efeito inflacionário no valor do estoque

O valor de $\$ 30,00$ corresponde ao custo de oportunidade inflacionário sobre o estoque, obtido pela aplicação da taxa de inflação $(10 \%)$ sobre o saldo inicial do estoque $(\$ 300,00)$.

Registro no 10: Contabilização de oportunidade sobre o estoque

O valor contabilizado como custo de oportunidade do estoque $(\$ 9,90)$ foi obtido pela aplicação da taxa real de custo de oportunidade de $3 \%$ sobre o valor corrigido do estoque $(\$ 300,00 \times 1,10=\$ 330,00)$. 
DEMONBTRAÇ̄̃O DE REBULTADOB - EXERCtcIO T4

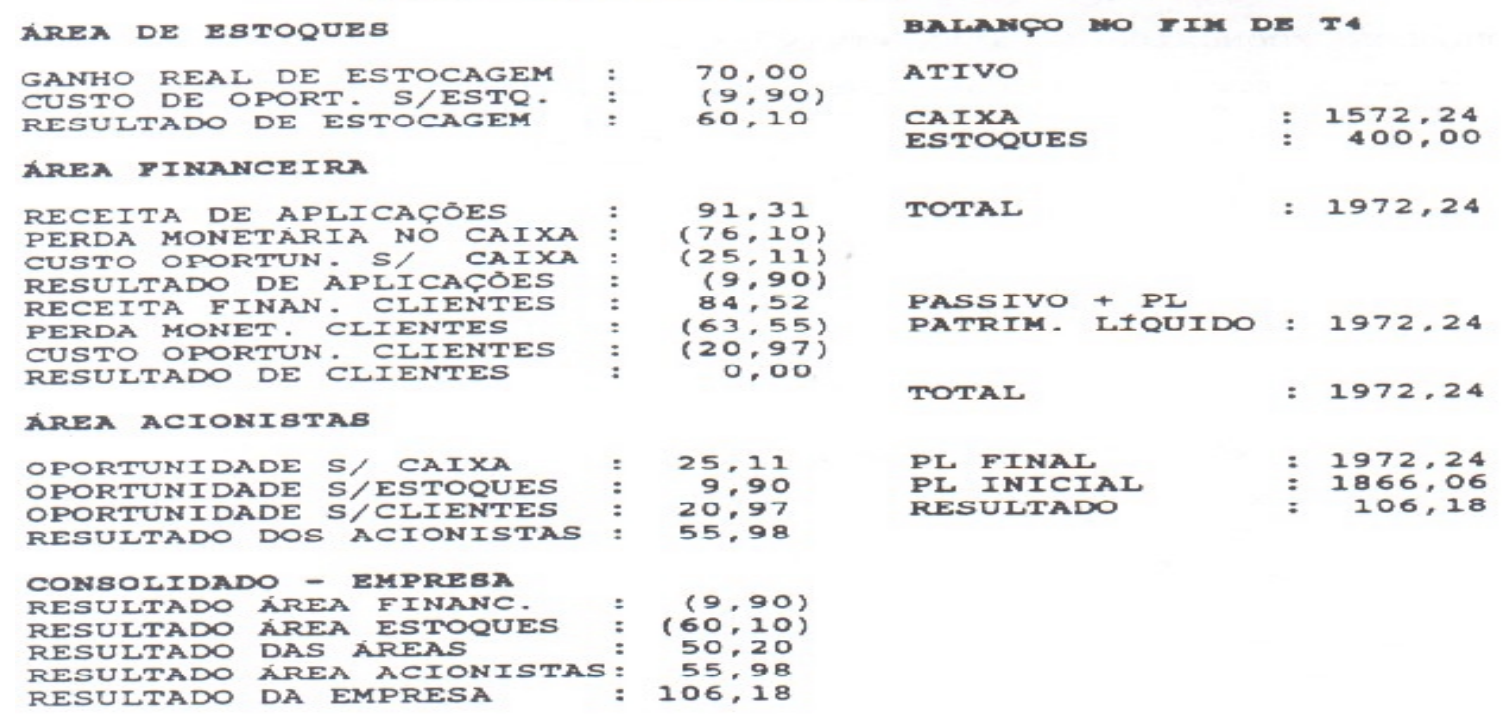

ANALISE DOS RESULTADOS - EXERCICIO T4

DESEMPENHO ECONOMICO DA ÁREA FINANCEIRA

A área financeira apresentou um resultado negativo de $\$ 9,90$ na aplicação de disponibilidade no mercado financeiro. Como já foi observado anteriormente esse prejuízo representa o custo da manutenção da liquidez exigida pelas operações da empresa.

O resultado da gestão de clientes foi nulo em função do recebimento ter sido efetuado no dia do vencimento.

\section{DESEMPENHO ECONOMICO DA ÁREA DE ESTOQUES}

A área de estoque apresentou um resultado positivo nesse período de $\$ 60,10$. O incremento de valor especifico do produto $(\$ 100,00)$ foi superior ao custo de oportunidade inflacionário $(\$ 30,00)$ e ao custo de oportunidade do acionista $(\$ 9,90)$.

\section{DESEMPENHO ECONOMICO DA ÁREA DE ACIONISTAS}

O resultado da área de acionistas foi positivo em $\$ 55,98$, em função da "cobrança" do custo de oportunidade pelos ativos mantido pela área financeira (dinheiro aplicado e valor a receber de clientes) e pela Área de estoques.

Desempenho econômico consolidado

O resultado global da empresa foi positivo em $\$ 106,18$.

\section{CONCLUSÃO}

Uma das [premissas de um trabalho cientifico é ter aplicabilidade ou importância a nível pratico ou teórico. Entendemos que o modelo apresentado é de grande utilidade para as empresas que incorporam no seu modelo de gestão as empresas estabelecidas neste trabalho.

É preciso que os contadores se conscientizem, para a sua própria evolução profissional e eficácia das suas atividades, que os gestores operativos constituem-se em uma classe especial de usuários da informação contábil. Eles são os responsáveis pela geração dos resultados econômicos e, em última estância, pela continuidade da empresa. Os gestores para o atingimento da eficácia empresarial, necessitam informações adequadas aos seus modelos de decisão.

Os contadores são responsáveis pela geração destas informações, e mais ainda, na sua esfera de atividade devem contribuir para efetivamente para a otimização do lucro global da empresa, controlando, assessorando e induzindo os gestores à tomada das melhores decisões para a empresa. Os contadores devem munir-se de recursos e instrumentos que possibilitem o atingimento desta missão. Um dos mais poderosos instrumentos que o contador detém é o sistema de informação contábil. 
Assim, o sistema de informação contábil não pode constituir-se em um instrumento burocrático, que tenha um fim em si mesmo. O sistema de informação de contabilidade deve ser uma ferramenta de gestão, ou seja auxiliar o seu gestor em suas atividades operativas, e simultaneamente, consubstanciar-se em um instrumento através do qual possa ser desenvolvido harmonicamente o ritual de "prestação de contas" entre os diversos níveis da estrutura de organização que surge com a delegação.

Para que isso seja possível, o sistema de informação contábil pode ser implementado a partir de preferências e experiências particulares e individuais. O sistema deve ser concebido a partir de sólidas premissas e incorporar conceitos que estejam sintonizados com o modelo de gestão adotado pela empresa.

Este trabalho, com as limitações consideradas, procura levar gestores e contadores à reflexão sobre uma possibilidade de modelo de sistema de informação contábil, que atenda suas necessidades informativas, e que possa dar uma contribuição pequena, porém efetiva, para o desenvolvimento das organizações. 